\title{
Kvinnen som ikke gjenkjente sitt eget ansikt
}

\author{
En kvinne fikk forverring av en hodepine som hadde debutert flere måne- \\ der i forveien. Hun utviklet deretter uvanlige kognitive symptomer og ble \\ innlagt i sykehus.
}

\begin{abstract}
Pasienten, som var i 40-årene, hadde fra tidligere astma og var slankeoperert med gastrisk bypass. Det siste halvåret før innleggelsen hadde hun vært sykmeldt grunnet en oksipital, bilateral hodepine som oppsto under en arbeidskonflikt, men vedvarte trass i omplassering i ny stilling. Hodepinen hadde et fluktuerende forløp, med hodepinefrie dager.

Den siste måneden var imidlertid hodepinen blitt konstant, og kvinnen hadde tatt paracetamol daglig og sumatriptan og diklofenak hyppig. Fastlegen hadde anbefalt bildediagnostisk utredning, men pasienten anså ikke dette som nødvendig, da hun tilskrev hodepinen muskulære spenninger grunnet stress.
\end{abstract}

Hodepine er en vanlig kontaktårsak i allmennpraksis og kan være en betydelig diagnostisk utfordring. Den internasjonale klassifiseringen av hodepinetilstander inkluderer over 200 ulike former for primær og sekundær hodepine (1). Klinisk kan det være vanskelig å skille mellom primær hodepine uten annen underliggende årsak og hodepine sekundært til annen tilstand. Av den grunn bør anamneseopptak og undersøkelse vektlegge «røde flagg» som kan gi mistanke om sekundær hodepine.

Viktige faresignaler oppsummeres ved akronymet «SNARET» (tab 1) (2). Uttrykket har sin opprinnelse fra det engelskspråklige «SNOOP» (3) og er blitt oversatt til norsk av Lars Jacob Stovner (personlig meddelelse). Hos denne pasienten hadde hode- pinen endret seg fra episodisk til konstant, men for øvrig var ingen «røde flagg» identifisert. Det er verdt å bemerke at hun hadde et daglig forbruk av analgetika, slik at kompliserende medikamentoverforbrukshodepine også burde mistenkes.

Dagen før innleggelsen hadde hodepinen igjen endret karakter. Den ble høyresidig og verst omkring øret, med utstråling til kinn og kjeve. Da samboeren kom hjem fra jobb påfølgende dag, oppfattet han henne som forvirret. Hun forsto ikke klokken eller innholdet $i$ tekstmeldinger. De oppsøkte legevakten, hvor hun overhodet ikke kjente seg igjen, selv om hun til daglig arbeidet i samme bygg.

Både hennes eget og samboerens ansikt var ugjenkjennelig for henne. Hun formidlet at hun visste svært godt hvem samboeren var, men at ansiktet hans fremsto som helt fremmed. PåTV-en på venteværelset hadde hun ikke gjenkjent noen av ansiktene fra serien Broen, men identifiserte likevel de ulike rollefigurene ut fra klærne. Hun hadde spurt samboeren hvorfor alle skuespillerne var blitt byttet ut.

Somatisk status og orienterende blodprøver ga ikke mistanke om indremedisinsk årsak. Pasienten ble oppfattet som konfus og ble henvist til nevrologisk vurdering $i$ akuttmottaket med spørsmål om transitorisk global amnesi (TGA).

Et symptombilde med endret hodepine og nyoppstått konfusjonstilstand gir grunn til å

\author{
Sverre Myren-Svelstad \\ s@myren-svelstad.no \\ Avdeling for nevrologi og klinisk nevrofysiologi \\ St. Olavs hospital \\ Tore Wergeland Meisingset \\ Avdeling for nevrologi og klinisk nevrofysiologi \\ St. Olavs hospital
}

\section{Kristin Wesnes}

Avdeling for nevrologi og klinisk nevrofysiologi St. Olavs hospital

Tabell 1 Faresignaler for hodepine oppsummert ved akronymet «SNARET», lett modifisert etter Stovner \& Sommerfelt (2). Gjengitt med tillatelse

\begin{tabular}{|c|c|}
\hline Start og utvikling & Hyperakutt start eller relativt nylig start med gradvis forverring \\
\hline Nevrologiske fenomener & $\begin{array}{l}\text { Varige nevrologiske utfall eller forbigående utfall som oppstår } \\
\text { plutselig og ikke utvikles gradvis, krampeanfall, personlighets- } \\
\text { endring }\end{array}$ \\
\hline Allmennsymptomer og -tegn & Feber, nakke-/ryggstivhet, påvirket allmenntilstand og vekttap \\
\hline Risikofaktorer & $\begin{array}{l}\text { Kreftsykdom, glaukom, overvekt, ukontrollert hypertensjon } \\
\text { og antitrombotisk medisin, særlig antikoagulasjonsmidler }\end{array}$ \\
\hline Eldre & Debut av hodepine etter 50 års alder \\
\hline Tidligere hodepinehistorie & Forverret eller endret hodepine \\
\hline
\end{tabular}




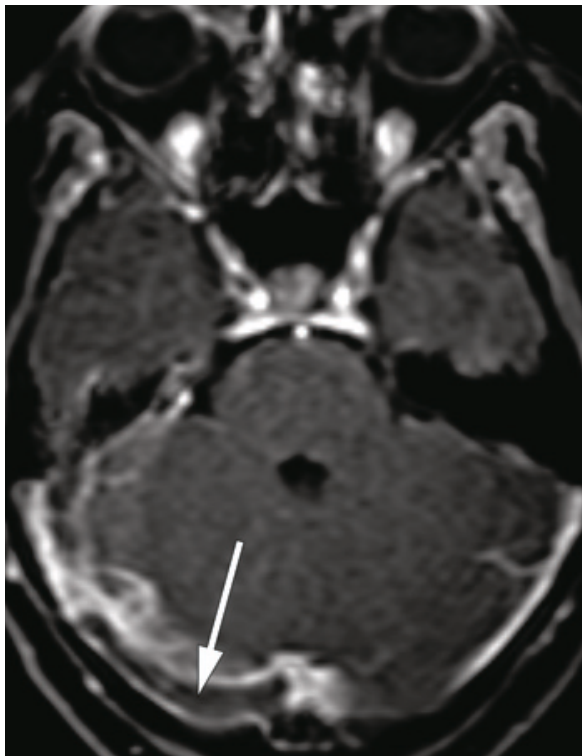

Figur 1 Trombe i høyre sinus transversus (pil) på T1-vektet MR-bilde etter kontrastinjeksjon

mistenke alvorlig sekundær årsak. Aktuelle differensialdiagnoser er i denne sammenhengen infeksjoner, cerebrovaskulære forstyrrelser og ekspansive prosesser.

I akuttmottaket var pasienten fortvilet og engstelig. Hun kunne redegjøre for sin egen sykehistorie, var orientert for tid og sted og husket personnummeret sitt og statsministerens navn. Det var normale vitale tegn blodtrykk 144/75 mm Hg, hjertefrekvens 60/ min, oksygensaturasjon $97 \%$ i romluft og temperatur $37,0^{\circ} \mathrm{C}$ målt med pannetermo-

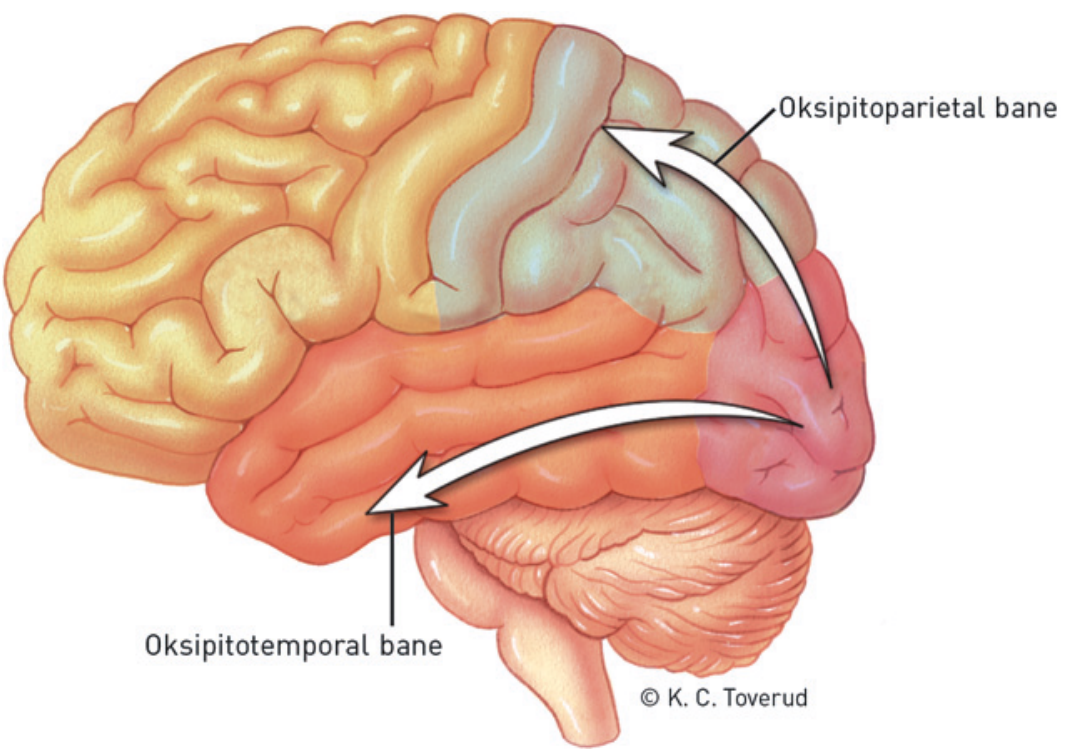

Figur 2 Det endelige synsinntrykket prosesseres etter den såkalte tostrømshypotesen i to baner. Oksipitallappens assosiasjonsfibre gårvia disse banene til henholdsvis parietallappen (pill) og temporallappen (pill. Utfallene hos vår pasient pekte mot affeksjon av den oksipitotemporale banen meter. Somatisk status var upåfallende, og det var ingen nakkestivhet.

Det var normal nevrologisk status, inkludert oftalmoskopi og synsfeltsundersøkelse ad modum Donders, og hun gjenkjente visuelt objekter som for eksempel en penn og taktilt sifferskrift $i$ hånden. Orienterende blodprøver var innenfor normalområdet, inkludert $D$ dimer på 0,3 mg/l (0,0-0,5 mg/l).

Siden pasienten var orientert og uten amnesi, var det ikke holdepunkter for at det kunne dreie seg om en konfusjonstilstand eller et amnesisyndrom. Infeksjon ble vurdert som lite sannsynlig, siden det ikke var feber eller nakkestivhet.

Hennes sykehistorie, med langvarig, gradvis tiltagende hodepine, er heller ikke typisk for subaraknoidalblødning. Andre cerebrovaskulære forstyrrelser og tumor cerebri var fortsatt aktuelle differensialdiagnoser.

Cerebral CT-undersøkelse viste intet sikkert, men det ble stilt spørsmål om det kunne være noe patologisk i intrakraniale vener. T1vektet MR-bilde av bakre skallegrop etter kontrastinjeksjon viste trombe $i$ høyre sinus transversus (fig 1), mens venstre side var åpen.

Behandling med lavmolekylært heparin i form av enoksaparin $1 \mathrm{mg} / \mathrm{kg} \times 2$ ble startet. Dagen etter innleggelsen var det full tilbakegang av de kognitive symptomene. Ved utskrivning var hun i god form.

\section{Diskusjon}

Kasuistikken er et eksempel på den store variasjonen i presentasjonsformer ved cere- bral venetrombose (CVT). Denne tilstanden omfatter trombedanning i cerebrale vener og durale sinuser, i sistnevnte tilfelle ofte kalt sinusvenetrombose.

Cerebral venetrombose er sjeldent, men sannsynligvis underdiagnostisert. Insidensen anslås til under 1 per 100000 per år. Cerebral venetrombose komplisert med cerebralt infarkt utgjør under $1 \%$ av alle hjerneslagstilfeller (4). For all venøs trombedanning kan patofysiologiske mekanismer forklares ut fra Virchows triade, altså forhold ved karvegg, hemodynamikk og/eller selve blodets trombedannende egenskaper (5). Viktige risikofaktorer for slik trombose er infeksjoner, medfødt trombofili og hyperkoagulopati som ved malignitet og systemiske revmatologiske sykdommer. I befolkningen ses venetrombose hyppigst hos personer under 40 år og er vanligere hos kvinner enn hos menn, trolig grunnet østrogenholdige prevensjonsmidler og graviditet (4).

Hos vår pasient ble det ikke avdekket medfødt trombofili. Anbefalte orienterende undersøkelser med røntgen thorax, mammografi og gynekologisk undersøkelse ga ikke mistanke om malignitet (6). Pasienten brukte hormonspiral (ikke østrogenholdig), i tillegg til daglige adrenergikum- og kortikosteroidholdige inhalasjoner (salmeterol-flutikason) og prednisolonkurer ved astmaeksaserbasjoner.

En dansk registerbasert pasient-kontrollstudie beskrev doseavhengig økt risiko for venøse tromboemboliske hendelser i underekstremiteter og lunger etter glukokortikoidbehandling (7). Risikoen var størst ved systemisk bruk, men økt risiko ble også beskrevet ved andre administrasjonsformer, som inhalasjon. Pasienter med venøs trombose $\mathrm{i}$ annen lokalisering ble ikke inkludert $\mathrm{i}$ denne studien, men glukokortikoider er $\mathrm{i}$ andre kilder oppført som risikofaktor for cerebral venetrombose (8). En sammenheng mellom vår pasients steroidbruk og cerebral venetrombose kan dermed ikke utelukkes.

Det er vist at D-dimer har en diagnostisk sensitivitet på $94 \%$ og en spesifisitet på $90 \%$ for cerebral venetrombose. Hos vår pasient var D-dimer falskt negativ. Falskt negativ D-dimer ses gjerne ved isolert hodepine, lang symptomvarighet og begrenset involvering av sinuser (9). Ved klinisk mistanke om cerebral venetrombose anbefales derfor bildediagnostisk utredning, hvor cerebral MR med venøs angiografi er gullstandard (4).

Det hyppigst rapporterte symptomet ved cerebral venetrombose er hodepine, som foreligger i opptil $90 \%$ av tilfellene og hos $9 \%$ er det eneste symptom. Mer enn halvparten av pasientene har en subakutt debut med økende hodepineintensitet over noen dager. For en tredel starter den akutt, med 
utvikling i løpet av et døgn, mens den i kun et mindretall av tilfellene har et kronisk forløp. Forhøyet intrakranialt trykk kan utover hodepine gi oppkast, papillødem og synsproblemer. Cerebral venetrombose kan også gi et fokalt syndrom, med fokalnevrologiske utfall og kramper, eller et encefalopatisyndrom, med bilaterale eller multifokale tegn og eventuell bevissthetsforstyrrelse (8).

Vår pasient hadde klare kognitive symptomer som pekte mot affeksjon av et spesielt område av hjernen. Det mest slående var at hun ikke klarte å gjenkjenne ansikter og kjenne seg igjen i kjente omgivelser. Utfall i hjernens evne til å tolke visuelle stimuli kan deles inn etter oksipitallappens assosiasjonsfibre til henholdsvis parietallappen («hvor»-utfall) og temporallappen («hva»-utfall) (fig 2) $(10,11)$. De visuelle agnosiene hører til sistnevnte. De defineres gjerne som manglende evne til å gjenkjenne gjenstander - uten at utfallet skyldes svekket sanseevne eller generell intellektuell reduksjon (altså «hva»-utfall).

Prosopagnosi (av gresk prosopon $=$ ansikt og gnosis = kunnskap) er en spesifikk visuell agnosi der man ikke kan identifisere et kjent ansikt ved å se på personen eller en avbildning, selv om man riktig identifiserer objektet som et ansikt og kan peke på særtrekk som briller, ansiktsbehåring eller stemmeleie (12). Nevrologen og forfatteren Oliver Sacks har i historien Mannen som forvekslet kona med en hatt beskrevet en pasient med prosopagnosi. Under et hjemmebesøk bemerket Sacks at det hang en rekke bilder på veggen av forskjellige personer - «Stort sett kjente han ikke igjen noen, hverken familie, kolleger, studenter eller seg selv. Han kjente igjen et portrett av Einstein fordi han la merke til den karakteristiske hårmanken og barten» (13).

Et mindre antall tilfeller som er blitt studert anatomisk og med CT- eller MR-undersøkelse, indikerer at prosopagnosi som oftest er assosiert med bilaterale lesjoner av mediale oksipitotemporale regioner. Det er rapportert unntak som skyldes unilateral skade, nesten alltid på høyre side (14). Hos vår pasient forelå det en trombe i sinus transversus på nettopp høyre side (fig 1). Venøs drenasje fra temporallappen skjer til sinus transversus via vena Labbé (vena anastomotica inferior), og stase i denne venen kan gi sirkulasjonsforstyrrelse i aktuelle hjerneområde. På MR-bildene var det ingen holdepunkter for diffusjonsavvik eller andre parenkymforandringer. Imidlertid lot ikke vena Labbé seg fremstille på aktuelle side, mens det var godt signal i kontralateral vene (fig 3). I sum anser vi at en sammenheng mellom MR-funn og pasientens kognitive symptomer er sannsynlig.

Ut fra humane studier med blant annet funksjonell MR-undersøkelse (fMR) er det sterke holdepunkter for at det finnes et lite område i temporallappens gyrus fusiformis hvor de fleste nevronene er ansiktsspesifikke (fig 4) (15). Oppfatningen at det er et «ansiktsområde» i gyrus fusiformis er en overforenkling, men formidles ukritisk i populærkulturen og dukket i pasientens rekonvalesensperiode opp i James Bondmet fast $i$ en stol utstyrt med avansert drillutstyr, truer erkeskurken med at han skal drille inn i Bonds gyrus fusiformis og slik ødelegge hans evne til ansiktsgjenkjenning. Utover ytterligere å sementere nevnte overforenkling er det vel nevroanatomisk mer graverende at boret rettes for lavt slik at det sikter mot processus mastoideus og ikke gyrus fusiformis. Bond-skurken er blitt gjenstand for en nevrokirurgisk reprimande i Nature (16).

Vår pasient hadde i tillegg til prosopagnosi problemer med å kjenne seg igjen på kjente steder, såkalt omgivelsesagnosi. Symptomet er nær knyttet til og ofte assosiert med prosopagnosi. Som for prosopagnosi er det oksipitotemporale forbindelser som er rammet, typisk høyresidig, skjønt hos enkelte pasienter er lesjonene bilaterale. Pasienten kan beskrive et sted ut fra hukomkjenner seg ikke igjen og går seg bort. Det er altså problemer med «hva» omgivelsene er, men ikke med «hvor» (17). Vår pasient hadde ingen vansker med intellektuelt å forstå at hun var i samme bygning som hun hadde kontor, men hun kjente seg ikke igjen.

Ved kontroll en måned senere var pasienten symptomfri, bortsett fra enkelte episoder med lavgradig hodepine. Da sammenhengen mellom steroidbruk og den cerebrale venefilmen Spectre. I en scene der Bond er reimelsen eller lokalisere det på et kart, men

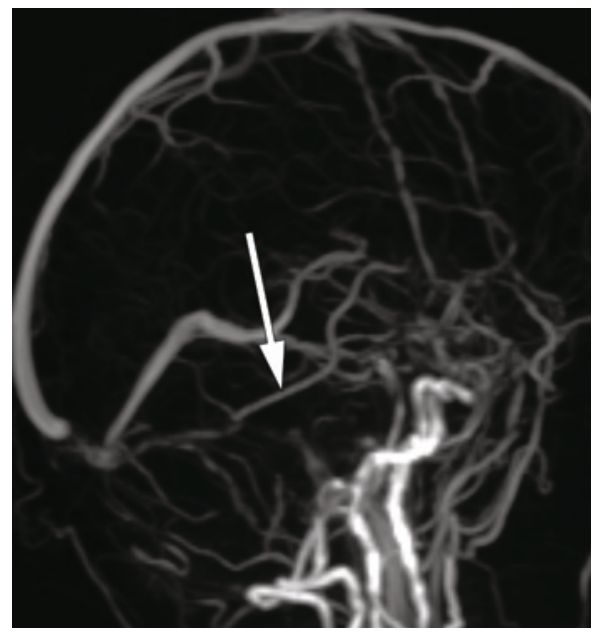

Figur 3 Venøs MR-angiografi (TOF-sekvens) viser god fylling av kontralaterale vena Labbé (pil), mens ipsilaterale vene ikke fremstilles

trombosen var usikker, anså vi tilstanden som idiopatisk og startet etter retningslinjer ett års antikoagulasjonsbehandling med warfarin (18).

Denne kasuistikken illustrerer et uvanlig klinisk bilde på cerebral venetrombose. I dette tilfellet opptrådte særegne kognitive symptomer som også har funnet veien til populærkulturen. Så vidt oss bekjent er prosopagnosi som symptom på cerebral venetrombose ikke tidligere rapportert.

Pasienten har gitt samtykke til at artikkelen blir publisert.

Vi takker Kjell Arne Kvistad for tolkning av MR-bilder.

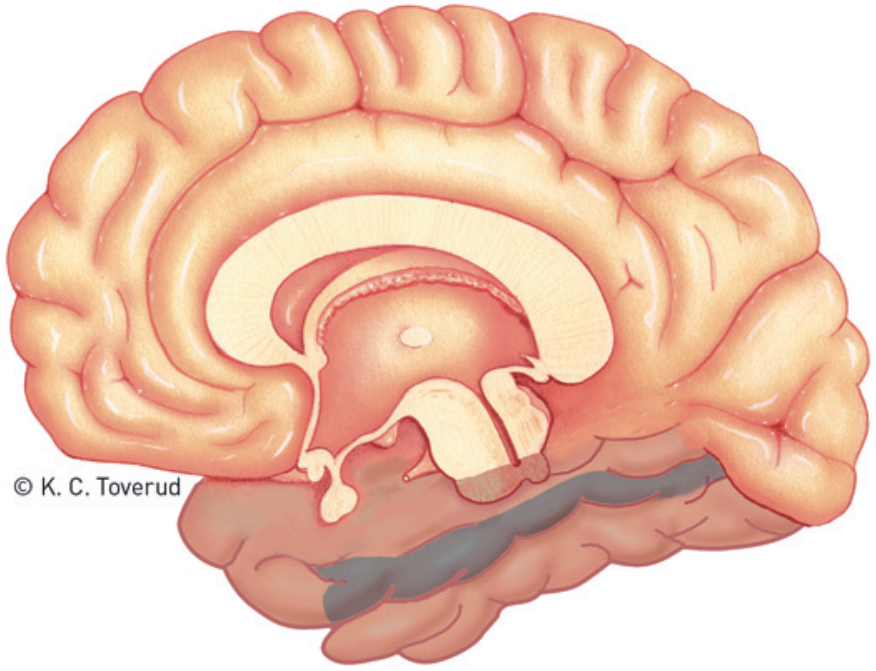

Figur 4 Høyre hemisfære sett fra medialsiden, med temporallappens gyrus fusiformis avmerket i blått. fMRstudier har vist at et område her er involvert i ansiktsgjenkjenning, gjerne omtalt som «fusiform face area» (FFA) (ikke spesifikt avmerket) 


\section{Sverre Myren-Svelstad (f. 1986)}

er lege i spesialisering i nevrologi.

Forfatter har fylt ut ICMJE-skjemaet og oppgir ingen interessekonflikter.

\section{Tore Wergeland Meisingset (f. 1986)}

er ph.d. og lege i spesialisering i nevrologi. Forfatter har fylt ut ICMJE-skjemaet og oppgir ingen interessekonflikter.

\section{Kristin Wesnes (f. 1981)}

er spesialist i nevrologi og konstituert overlege. Forfatter har fylt ut ICMJE-skjemaet og oppgir ingen interessekonflikter.

\section{Litteratur}

1. The International Classification of Headache Disorders. 3rd edition (beta version). Cephalalgia 2013; 33: 629-808.

2. Stovner LJ, Sommerfelt K. Hodepine. I: Gjerstad L, Helseth E, Rootwelt T, red. Nevrologi og nevrokirurgi fra barn til voksen. 5. utg. Høvik: Forlaget Vett \& Viten, 2010: 399-411.

3. Dodick DW. Diagnosing Headache: Clinical Clues and Clinical Rules. Adv Stud Med 2003; 3: 87-92.

4. Johnsen H-J, Vorhaug A, Kvistad KA. Cerebral venetrombose - diagnostikk og behandling. Tidsskr Nor Lægeforen 2007; 127: 1069-73.

5. Chung I, Lip GY. Virchow's triad revisited: blood constituents. Pathophysiol Haemost Thromb 2003. 33: $449-54$

6. Carrier M, Lazo-Langner A, Shivakumar S et al. Screening for Occult Cancer in Unprovoked Venous Thromboembolism. N Engl J Med 2015 373: 697-704.

7. Johannesdottir SA, Horváth-Puhó E, Dekkers OM et al. Use of glucocorticoids and risk of venous thromboembolism: a nationwide population-based casecontrol study. JAMA Intern Med 2013; 173: 743-52.

8. Caplan LR. Cerebral venous thrombosis. I: Caplan LR, red. Caplan's Stroke. 4. utg. Philadelphia: Elsevier, 2009: 554-77.

9. Dentali F Squizzato A Marchesi $C$ et al. D-dimer testing in the diagnosis of cerebral vein thrombosis: a systematic review and a meta-analysis of the literature. J Thromb Haemost 2012; 10: 582-9.

10. Goodale MA, Milner AD. Separate visual pathways for perception and action. Trends Neurosci 1992: 15: $20-5$.

11. Ungerleider LG, Mishkin M. Two cortical visual systems. I: Ingle DJ, Goodale MA, Mansfield RJW. red. Analysis of visual behavior. Cambridge, MA: Massachusetts Institute of Technology, 1982: 549-86.

12. Ropper A, Samuels M, Klein J. Neurologic disorders caused by lesions in specific parts of thecCerebrum. I: Ropper A, Samuels M, Klein J, red. Adams and Victor's Principles of Neurology. 10. utg. New York: McGraw-Hill Education, 2014: 479.

13. Sacks O. Mannen som forvekslet kona med en hatt og andre kliniske historier. Oslo: Cappelen, 1987.

14. Barton JJ. Structure and function in acquired prosopagnosia: lessons from a series of 10 patients with brain damage. J Neuropsychol 2008; 2: 197-225.

15. Bernstein M, Yovel G. Two neural pathways of face processing: A critical evaluation of current models. Neurosci Biobehav Rev 2015: 55: 536-46.

16. Cusimano MD. Entertainment: Bond villain fails neuroanatomy. Nature 2015; 528: 479

17. Landis T, Cummings JL, Benson DF et al. Loss of topographic familiarity. An environmental agnosia. Arch Neurol 1986: 43: 132-6.

18. Einhäupl K, Stam J, Bousser MG et al. EFNS guideline on the treatment of cerebral venous and sinus thrombosis in adult patients. Eur J Neurol 2010; 17: 1229-35. 